\title{
Tratamiento selectivo de los episodios de neutropenia febril en niños con cáncer. Comité de Infectología, Programa Infantil Nacional de Drogas Antineoplásicas (PINDA)
}

M. ELENA SANTOLAYA DE P., ANA M. ÁLVAREZ P., CARMEN L. AVILÉS L., ANA BECKER K., JOSÉ COFRÉ G., ERNESTO PAYÁ G., JAIME RODRÍGUEZ T., CARMEN SALGADO M., PAMELA SILVA L., JUAN TORDECILLA C., MÓNICA VARAS P., MILENA VILLARROEL C., TAMARA VIVIANI S. y MARCELA ZUBIETA A.

\section{Selective treatment of febrile neutropenia in pediatric cancer patients}

Management of pediatric patients with cancer and febrile neutropenia (FN) requires appropriate identification of children at high or low risk of acquiring invasive bacterial infections (IBI), in order to implement selective treatment strategies. Based on international and our own research experience, we propose recommendations for diagnostic screening and management of children with cancer and FN according to their risk of IBI. All pediatric patients with FN must be admitted to hospital for at least 24 hours. During this period clinical and laboratory evaluations are aimed to determine their risk of IBI and to identify potential infectious focii. High risk patients should be managed in the hospital until recovery. Low risk patients can be managed as outpatients. Antimicrobial selection and possible adjustments to therapy will depend on the identification of an infectious focus, and/or local epidemiology and susceptibility patterns. Patients will require periodic clinical and laboratory reevaluation (day 3, 5 and 7 of evolution or more frequently if clinically indicated) irrespective of their risk category; response to treatment can be defined as favorable or unfavorable based in preestablished clinical and laboratory criteria in order to monitor the success of selected strategies.

Key words: Cancer; Pediatrics; Febrile neutropenia; Treatment.

Palabras claves: Cáncer; Pediatría; Neutropenia febril; Tratamiento.

\section{Definiciones}

Neutropenia severa: Recuento absoluto de neutrófilos $(\mathrm{RAN})<500$ céls $/ \mathrm{mm}^{3}$.

Fiebre: Una medición de temperatura axilar $>38,5^{\circ} \mathrm{C}$ o dos mediciones $>38,0^{\circ} \mathrm{C}$ en un período de dos horas.

Infección bacteriana invasora: Incluye todas las bacteriémicas (SNC, osteoarticular, endocarditis, etc) o no bacteriémicas con localizaciones pulmonar, intraabdominal, renal, tejidos blandos profundos. Excluye infecciones superficiales de piel y mucosas.

Infección fúngica profunda: Incluye todas las fungiémicas (candidemia, endocarditis, etc) o no fungiémicas viscerales.

\begin{abstract}
Antecedentes
Existe consenso en la literatura médica que los episodios de neutropenia febril (NF) en pacientes con cáncer obedecen a tres grandes causas: infecciones bacterianas demostradas, infecciones bacterianas probables e infecciones virales agudas, existiendo un grupo menor catalogado de fiebre de origen desconocido en el cual no se llega a una interpretación clínica satisfactoria y su exploración etiológica es negativa ${ }^{1}$. Las implicancias pronósticas de estos grupos son enteramente diferentes.

En la década del 90 se han acuñado los conceptos de NF con alto y bajo riesgo de cursar con una infección bacteriana invasora (IBI) ${ }^{2-5}$, lo
\end{abstract}

Hospital Luis Calvo Mackenna, Santiago (MES de P, JCG, MVC); Hospital San Juan de Dios, Santiago (AMAP, MVP); Hospital San Borja Arriarán, Santiago (CLAL, PSL); Hospital Sótero Del Río, Santiago (ABK, TVS); Hospital Exequiel González Cortés, Santiago (EPG, CSM, MZA); Hospital Roberto Del Río, Santiago (JRT, JTC).

Recibido: 24 mayo 2004

Aceptado: 31 mayo 2004 
que permite emplear estrategias diferenciadas según el riesgo que entrañe cada episodio ${ }^{6-9}$.

En nuestro medio, hemos desarrollado como Comité de Infectología del Programa Infantil Nacional de Drogas Antineoplásicas (PINDA), estudios de investigación con el propósito de crear y validar un modelo de predicción de riesgo de IBI en los episodios de NF, para posteriormente ofrecer acciones diagnósticas y terapéuticas proporcionadas a la gravedad de cada episodio.

Nuestros principales resultados han mostrado que en 447 episodios de NF estudiados entre 1996 y 1997 fueron 5 los parámetros detectables al momento del ingreso que estuvieron asociados a un riesgo significativamente mayor de IBI: nivel sérico de proteína C reactiva $(\mathrm{PCR})>$ a $90 \mathrm{mg} / \mathrm{L}$; hipotensión arterial; recaída de leucemia; recuento de plaquetas < a 50.000/ $/ \mathrm{mm}^{3}$; e intervalo de tiempo entre el término del último ciclo de quimioterapia y el inicio de la fiebre $<7$ días (Tabla 1$)^{10}$. Con estos datos, validados en forma prospectiva en 267 episodios de NF, reclutados entre 1998 y 1999, creamos un modelo de predicción de riesgo con una sensibilidad, especificidad, valor predictor positivo y negativo de $92,68,78$ y $90 \%$ respectivamente (Tabla 2$)^{11}$.

Como una tercera etapa, entre los años 2000 y 2003 comparamos en 149 episodios de NF de bajo riesgo, la eficacia clínica y costo de dos estrategias terapéuticas: tratamiento ambulatorio versus hospitalizado. Nuestros resultados mostraron una eficacia terapéutica de 95 y $93 \%$ respectivamente, siendo la modalidad de tratamiento ambulatorio significativamente más económica $(\mathrm{p}=0,003)(\text { Tabla } 3)^{12}$.

\section{Etiología de las infecciones bacterianas durante los episodios de neutropenia febril}

Los grupos oncológicos pediátricos de la Región Metropolitana pertenecientes al PINDA, atienden entre 300 y 350 episodios de NF por año, de los cuales 60 y $40 \%$ corresponden a alto y bajo riesgo de IBI, respectivamente. La mortalidad global ha sido de 3 a $4 \%$, y se concentró en el grupo de alto riesgo.

Tabla 1. Variables de ingreso independientemente asociadas con riesgo de infección bacteriana invasora, por orden de significancia

\begin{tabular}{llc}
\hline Variable & RR & IC 95\% \\
\hline PCR sérica > 90 mg/L & 4,2 & $3,6-4,8$ \\
Presencia de hipotensión arterial & 2,7 & $2,3-3,2$ \\
Recaída de leucemia & 1,8 & $1,7-2,3$ \\
Rcto plaquetas < 50.000/mm & $1,7-2,2$ \\
< 7 ds lapso última QT-inicio fiebre & 1,7 & $1,1-1,6$ \\
\hline
\end{tabular}

Referencia 10.

Tabla 2. Criterios de alto o bajo riesgo de infección bacteriana invasora en episodios de neutropenia febril

\begin{tabular}{|c|c|}
\hline Alto riesgo & Bajo riesgo \\
\hline $\begin{array}{l}\text { Presencia de dos o más factores } \\
\text { cualquiera }\end{array}$ & Ausencia de factores de riesgo \\
\hline $\begin{array}{l}\text { Presencia de alguno de los siguientes como factor único: } \\
\text { PCR > } 90 \mathrm{mg} / \mathrm{L} \\
\text { Hipotensión arterial } \\
\text { Alguno de los siguientes tipos de cáncer: } \\
\text { Leucemia en recaída } \\
\text { LLA de alto riesgo } \\
\text { Leucemia mieloide aguda } \\
\text { Linfoma no Hodgkin B y de células grandes } \\
\text { Neuroblastoma etapa IV } \\
\text { Recaída de tumores sólidos }\end{array}$ & $\begin{array}{l}\text { Presencia de alguno de los siguientes como factor único: } \\
\text { Rcto. plaquetas }<50.000 / \mathrm{mm}^{3} \\
\text { Menos de } 7 \text { días desde la última quimioterapia }\end{array}$ \\
\hline
\end{tabular}

Adaptado de referencia 11. 
Tabla 3. Costo de tratamiento ambulatorio y hospitalizado de los episodios de neutropenia febril con bajo riesgo de IBI en niños con cáncer (2002-2003)

\begin{tabular}{lccc}
\hline \multicolumn{1}{c}{ Item } & Ambulatorio & Hospitalizado & P \\
\hline Hospitalización & $\$ 138.388^{*}$ & $\$ 333.713^{*}$ & 0,0001 \\
Insumos & $\$ 11.729$ & $\$ 9.844$ & 0,57 \\
Laboratorio & $\$ 105.371$ & $\$ 96.044$ & 0,37 \\
Medicamentos & $\$ 181.161$ & $\$ 189.712$ & 0,75 \\
Movilización & $\$ 9.297$ & $\$ 2.650$ & 0,003 \\
Total & $\$ 445.948$ & $\$ 631.965$ & 0,003 \\
\hline
\end{tabular}

Referencia 12

* 1 dolar $=640$ pesos (Julio 2004)

La identificación microbiológica se alcanzó en 25 a $30 \%$ de los episodios (15\% correspondieron a sangre y 10 a $15 \%$ a otras muestras: orina, lesiones de piel, deposiciones, etc) ${ }^{13}$. Este porcentaje ha sido variable según el tipo de episodio. En los episodios con alto riesgo de IBI se obtuvo cultivos positivos en 47 a $50 \%$ de los casos (sangre $25 \%$, cultivos de catéter venoso central $11 \%$, orina $9 \%$, deposiciones $2 \%$ y otras localizaciones $3 \%$ ). Las etiologías más frecuentemente detectadas fueron Escherichia coli (26\%), Staphylococcus aureus (20\%), Staphylococcus coagulasa negativa (18\%), Klebsiella pneumoniae (10\%) y Pseudomonas aeruginosa $(5 \%)^{10,11}$. En los episodios con bajo riesgo de IBI la recuperación bacteriana fue mínima $(1-2 \%)^{12}$.

Esta experiencia multicéntrica ha entregado argumentos sólidos que permiten efectuar recomendaciones, diferenciadas según riesgo de IBI, para el manejo de los episodios de NF en niños con cáncer que son atendidos en la Región Metropolitana. Los grupos médicos que trabajan con pacientes oncológicos pediátricos en otras regiones del país pueden adoptar este documento como base conceptual al momento de elaborar sus propias recomendaciones y adaptarlas según las experiencias institucionales y recursos disponibles.

\section{Recomendaciones}

El Comité de Infectología del PINDA estima que una clasificación de riesgo de IBI que ha sido validada en nuestro medio, permite ofrecer a cada paciente la mejor estrategia de manejo, sin exponerlo a riesgos clínicos derivados de su manejo selectivo. Se describen a continuación las recomendaciones para el estudio de los episodios de NF y su tratamiento, diferenciados según riesgo clínico.

\section{Exploración de laboratorio al ingreso}

Orientada a detectar foco(s) infeccioso(s) y su(s) etiología(s) y medir los parámetros empleados en la predicción de riesgo.

Exámenes a solicitar en todo paciente con NF: Hemograma con recuento de plaquetas; proteína $\mathrm{C}$ reactiva cuantitativa; radiografía de tórax AP y lateral; orina completa y urocultivo; hemocultivos: en paciente sin catéter venoso central (CVC), dos muestras por punción venosa (hemocultivo periférico), con un lapso de 20 minutos entre sí. Volumen según edad: lactantes $2 \mathrm{cc}$, preescolares $4 \mathrm{cc}$, escolares 6-10 cc. En paciente con CVC, una muestra de cada lumen del dispositivo (hemocultivo central) y simultáneamente un hemocultivo periférico. Las técnicas de hemocultivo convencional en equipo automatizado (Bactec $\AA$, Bact/Alert $\AA$ u otros que permitan medir el tiempo diferencial de crecimiento) y de hemocultivo cuantitativo (técnica que permite efectuar recuentos microbianos por $\mathrm{ml}$ de sangre extraída) son complementarias entre sí para el estudio de pacientes portadores de CVC de larga duración ${ }^{14}$.

\section{Exámenes a solicitar según orientación clínica:}

- Piel. Cultivo bacteriano de lesiones dérmicas que sean abordables por punción/aspiración. Frente a sospecha de infección por miembros de la familia Herpesviridae (virus varicela, virus herpes simplex tipo I y II) se recomienda tinción de Tzank, muestra para cultivo viral o para reacción de polimerasa en cadena (RPC), según disponibilidad.

- Mucosas. Examen directo (Gram, optativo tinción de Tzank) de las lesiones ulceradas o exudativas de mucosas oral/ocular/genital o anal. El cultivo de superficies mucosas se solicitará sólo si se sospecha un patógeno específico (ej: 
Streptococcus pyogenes, S. aureus o Candida albicans en mucosa faríngea, Neisseria gonorrhoeae, Candida sp o Chlamydia trachomatis en mucosa genital). Los cultivos de la cavidad oral, mucosa genital y de región perineal arrojan resultados habitualmente difíciles de interpretar (infección versus colonización).

- Muestra respiratoria. Si se sospecha etiología viral, tomar muestra de aspirado nasofaríngeo y realizar pruebas rápidas (IFD/IFI/ELISA) o aislamiento para VRS, ADV, virus influenza y parainfluenza. En paciente con infiltrado pulmonar difuso se recomienda ampliar el estudio, solicitando IgM para Mycoplasma pneumoniae y lavado broncoalveolar (LBA). La muestra obtenida por LBA debe ser estudiada para búsqueda de bacterias, virus y hongos, de acuerdo a la orientación clínica y epidemiología local. Las recomendaciones para el estudio de muestra de LBA se resumen en la Tabla 4.

- LCR: Citoquímico, Gram y cultivo si existe la sospecha de una infección meníngea.

- Deposiciones: Coprocultivo, estudio de virus entéricos y de parásitos en pacientes en que se sospeche la existencia de un foco enteral.

\section{Clasificación de riesgo de infección bacteriana invasora}

En base a los criterios detallados en la Tabla 2 se clasificará a cada episodio de NF en alto o bajo riesgo de IBI iniciándose un manejo diferencial como se detalla a continuación.

\section{Pacientes con alto riesgo de infección bacteriana invasora (Figura 1)}

Deben ser ingresados en box individual para minimizar el riesgo de adquirir infecciones nosocomiales durante su permanencia en las unidades clínicas de hospitalización.

Hospitalización en Unidad de Cuidados Intensivos. El paciente con inestabilidad hemodinámica debe ser internado en una UCI, idealmente en un régimen de aislamiento protector, hasta alcanzar su estabilización. Debe hacerse expresa mención que la no disponibilidad de aislamiento en UCI no debe constituir causal para negar su admisión en esta unidad.

Tratamiento antimicrobiano. El esquema antimicrobiano debe cumplir con los siguientes requisitos: seleccionar fármacos de administración intravenosa; espectro con cobertura para bacilos gramnegativos y cocáceas grampositivas, adecuados según epidemiología y patrones de
Tabla 4. Estudio solicitado en muestra de lavado broncoalveolar

\author{
Estudio bacteriano \\ Tinción de Gram \\ Tinción ácido alcohol resistente (Ziehl-Neelsen) \\ Cultivo bacteriológico corriente \\ Cultivo de anaerobios \\ Cultivo de Koch \\ RPC para Mycoplasma pneumoniae y Chlamydia \\ pneumoniae
}

\section{Estudio viral}

Inmunofluorescencia indirecta para VRS, ADV, influenza y parainfluenza

Cultivo ADV

Cultivo CMV, detección rápida de antígenos de CMV (shell vial)

RPC para herpes simplex

\section{Estudio de hongos}

Tinción de $\mathrm{KOH}$

Cultivo de hongos

RPC para hongos*

Galactomanano de Aspergillus*

Tinción de Gromori Grocott (Pneumocystis jiroveci) RPC para Pneumocystis jiroveci

* Técnicas en evaluación, disponibles sólo en centros de investigación.

susceptibilidad antimicrobiana de cada institución; adecuar los esquemas según la presentación clínica de focos infecciosos; usar las dosis recomendadas en Tablas 6,7 y 8 .

En pacientes con foco clínico evidente se recomienda adicionar a la terapia de amplio espectro antibacteriano el fármaco más indicado según el foco existente (Tabla 5).

En pacientes sin foco clínico evidente se recomienda usar asociaciones que incluyan un $\beta$-lactámico con acción anti estafilocóccica más un aminoglicósido y una cefalosporina de $3^{\circ}$ generación con o sin actividad anti Pseudomonas. Alternativas recomendables son: cloxacilina + amikacina + cefotaxima; cloxacilina + amikacina + ceftazidima.

Uso empírico de vancomicina. El uso empírico de vancomicina en reemplazo de cloxacilina no debe ser una conducta generalizada en los pacientes oncológicos pues su uso reiterado favorece la selección de cocáceas grampositivas resistentes. En la experiencia de algunos centros pertenecientes al PINDA ya se han detectado cepas de Enterococcus sp con susceptibilidad disminuida a vancomicina. Además ya se han reportado en el mundo cepas de $S$. aureus resistentes a vancomicina, fenómeno ante el cual los hospitales chilenos no están libres de riesgo. Para 


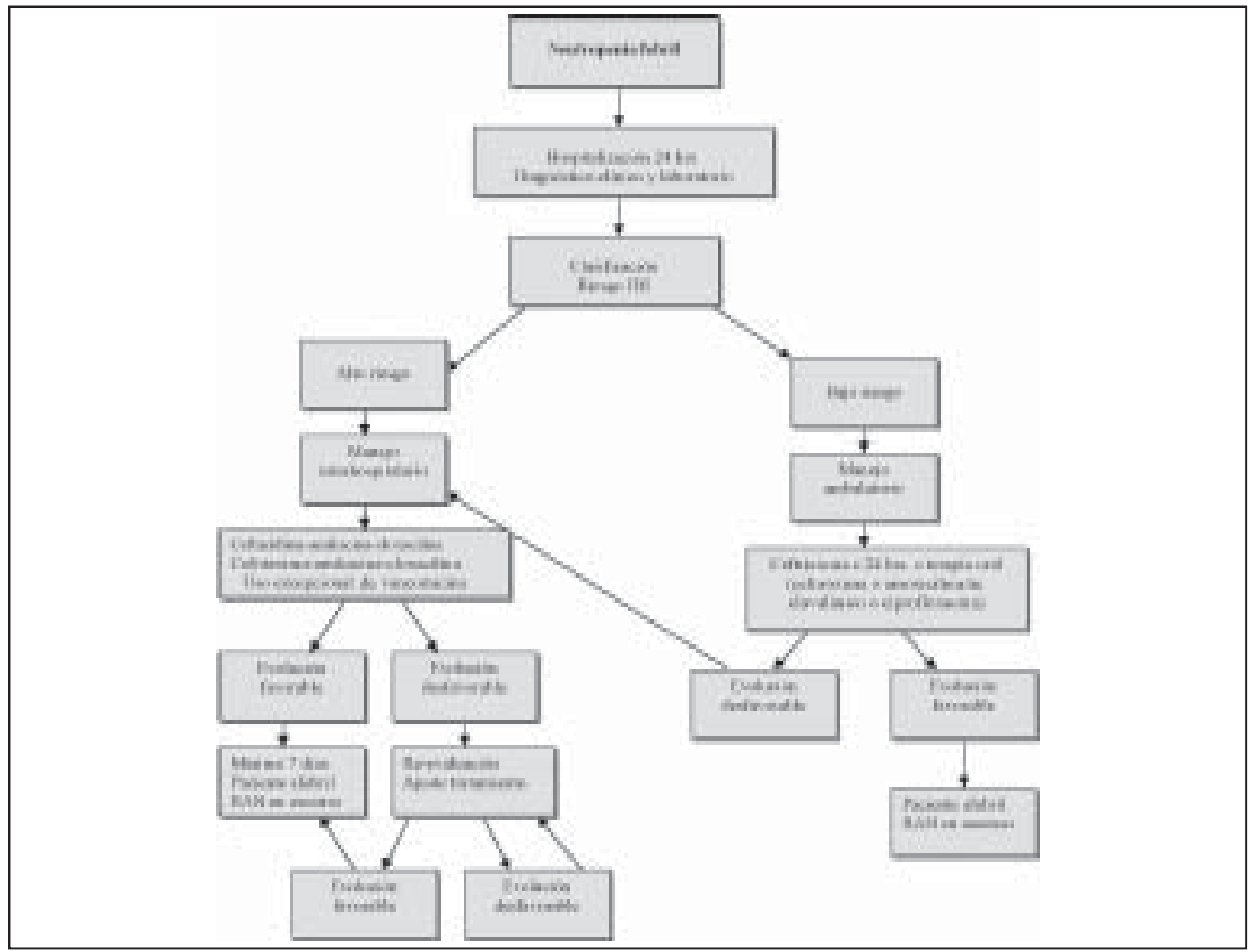

Figura 1. Algoritmo propuesto para el manejo diferencial de los pacientes con cáncer, neutropenia y fiebre, según riesgo de infección bacteriana.

instituciones donde la resistencia in vitro de $S$. aureus a meticilina - SAMR (equivalente en términos terapéuticos a resistencia a cloxacilina) tiene una incidencia superior al $30 \%$, se recomienda el uso empírico de vancomicina en las siguientes condiciones clínicas, que sugieren fuertemente la etiología estafilocóccica: pacientes con NF de alto riesgo y compromiso hemodinámico; la existencia de los siguientes focos infecciosos: endocarditis, artritis séptica, osteomielitis aguda, celulitis, miositis o fascitis necrosante; sospecha de infección de válvula derivativa de SNC; exantema escarlatiniforme o urticarial; fuerte presunción clínica de infección de CVC de larga duración, tales como eritema y/o secreción purulenta en el sitio de inserción o en el trayecto subcutáneo; signos clínicos sugerentes de bacteriemia (calofríos, compromiso del estado general), luego de realizar infusión por CVC de larga duración; infección documentada por SAMR en los últimos 3 meses. La presencia de un CVC en el paciente no debe constituir, per se, motivo para el uso empírico de vancomicina.
Seguimiento de los pacientes. Todos los pacientes con NF de alto riesgo serán evaluados diariamente hasta que el RAN sea $>500 / \mathrm{mm}^{3}$ y estén afebriles durante 24 horas o más.

Evaluación clínica. Debe contemplar: control de estado hemodinámico, temperatura y búsqueda acuciosa de posibles focos de infección.

Medición seriada de PCR. Se debe realizar los días 2 y 3 y, de allí en adelante, de acuerdo a la evolución clínica.

Control hematológico. Se debe medir el RAN, recuento absoluto de monocitos (RAM) y recuento de plaquetas al día 2, y luego cada dos días, hasta que el RAN sea $>500 / \mathrm{mm}^{3}$, RAM $>100 / \mathrm{mm}^{3}$, y el recuento de plaquetas $>50.000 / \mathrm{mm}^{3}$.

Control bacteriológico. Al día 3, se recomienda controlar todo cultivo de sangre $\mathrm{u}$ otro líquido estéril cuyo cultivo obtenido al ingreso del paciente hubiera resultado positivo. Los cultivos 
Tabla 5. Tratamiento antimicrobiano recomendado en niños con neutropenia febril en presencia de foco clínico

\begin{tabular}{|c|c|c|}
\hline Localización & Antimicrobianos & Nota \\
\hline Catéter vascular & Incluir cloxacilina o vancomicina & Uso prudente de vancomicina \\
\hline Cavidad orofaríngea & Adición antianaerobios & Ideal penicilina \\
\hline Esófago: & $\begin{array}{l}\text { Adición anfotericina B } \\
\text { Considerar aciclovir }\end{array}$ & Requiere biopsia y cultivo \\
\hline Enteral: & Incluir cefalosporinas $3^{\mathrm{a}} \mathrm{g}$ & $\begin{array}{l}\text { En sospecha de tiflitis } \\
\text { considerar metronidazol }\end{array}$ \\
\hline Cutánea: & $\begin{array}{l}\text { Incluir cloxacilina } \\
\text { Considerar metronidazol } \\
\text { Ceftazidima + amikacina }\end{array}$ & $\begin{array}{l}\text { En celulitis perianal } \\
\text { En ectima gangrenoso }\end{array}$ \\
\hline Ótica & Cefalosporina $3^{\mathrm{a}} \mathrm{g}$ & Cultivo oído medio \\
\hline Sinusal: & $\begin{array}{l}\text { Cloxacilina + cefalosporina } 3^{\mathrm{a}} \mathrm{g} \\
\text { Considerar antianaerobios } \\
\text { Considerar antifúngicos }\end{array}$ & $\begin{array}{l}\text { Requiere cultivo senos } \\
\text { paranasales por punción } \\
\text { (Aspergillus, Mucor) }\end{array}$ \\
\hline Pulmonar consolidante & Cloxacilina + cefalosporina $3^{\mathrm{a}} \mathrm{g}$ & \\
\hline Pulmonar intersticial & Adición macrólidos y cotrimoxazol & Requiere LBA \\
\hline Urinario: & Incluir aminoglicósido o cefalosporina $3^{\mathrm{a}} \mathrm{g}$ & \\
\hline Meníngea: & Cefalosporina $3^{\mathrm{a}} \mathrm{g}+$ ampicilina + aminoglicósido & Considerar Listeria monocytogenes \\
\hline Osteoarticular: & Cloxacilina + cefalosporina $3^{\mathrm{a}} \mathrm{g}$ & Uso adecuado vancomicina \\
\hline
\end{tabular}

obtenidos en el día 3 que persistieran positivos, se repetirán cada dos días (independientemente de los ajustes terapéuticos efectuados) hasta evidenciar su esterilización.

Evaluación de la respuesta terapéutica. Se recomienda evaluar la eficacia del tratamiento antimicrobiano luego de 72 horas de instaurado, y luego al día 5 y 7 de evolución. La evolución debe ser catalogada como favorable o desfavorable, de acuerdo a los siguientes parámetros: estado hemodinámico, curva térmica, hallazgos del examen físico y evaluación de niveles séricos de PCR.

Evolución favorable. Incluye todos los siguientes requisitos: estabilización hemodinámica; curso afebril o caída paulatina y significativa de la fiebre; resolución progresiva de focos infecciosos presentes al ingreso y ausencia de nuevos focos de infección; descenso significativo de PCR sérica a partir del tercer día (se considera significativa una disminución de al menos $30 \%$ del valor observado el día anterior); negatividad de nuevos cultivos que fueran positivos al ingreso.

Los pacientes continuarán su terapia antimicrobiana en curso dependiendo de la resolución clínica de el (los) foco(s) infeccioso(s), hasta completar un mínimo de 7 días. Parte de este plazo puede cumplirse como tratamiento oral.

El tratamiento antimicrobiano podrá ser ajustado de acuerdo a:

Hallazgos bacteriológicos. Pese a tener un aislamiento bacteriano, se recomienda mantener una antibioterapia que cubra bacilos gramnegativos y cocáceas grampositivas hasta que el RAN sea $>500 / \mathrm{mm}^{3}$. Si los microorganismos aislados son susceptibles al tratamiento empírico inicial se podrá continuar con éste hasta cambiar a la vía oral. Se justifica continuar empleando ceftazidima sólo en caso de aislamiento de $P$. aeruginosa. Frente a la presencia de $S$. aureus o $S$. coagulasa negativa susceptible a oxacilina, el paciente deberá recibir cloxacilina, aunque su terapia de inicio haya sido con vancomicina.

Cada vez que sea posible, se recomienda el cambio a terapia oral, condicionado por una buena tolerancia digestiva y el uso de fármacos con buena biodisponibilidad y amplio espectro de acción (cefuroxima axetil, amoxicilina/ácido clavulánico, ciprofloxacina).

Precisión de foco clínico: En este caso se debe ajustar la terapia específica según cuál sea el foco clínico (Tabla 5). Se recomienda el cambio oportuno a antimicrobianos orales completando un tratamiento mínimo de 7 días, hasta que 
el paciente entere 48 horas de evolución afebril y el RAN sea $>500 / \mathrm{mm}^{3}$.

Ausencia de foco clínico: En este caso se recomienda mantener el tratamiento empírico inicial o realizar un cambio a terapia oral (cefuroxima axetil, amoxicilina/ácido clavulánico, ciprofloxacina) completando un tratamiento mínimo de 7 días, hasta que el paciente esté afebril y el RAN vaya en ascenso.

Evolución desfavorable. Incluye uno o más de los siguientes requisitos: inestabilidad hemodinámica no atribuible a perdida de volumen; fiebre persistente más allá de 72 horas (temperatura $>38^{\circ} \mathrm{C}$ en dos tomas diarias), sin tendencia a disminuir; aparición de un nuevo foco infeccioso sugerente de IBI; curva de PCR estacionaria (reducción no significativa a partir del día 3) o en ascenso; persistencia de cultivos positivos luego de 72 horas de tratamiento.

El hallazgo de evolución desfavorable implica el cambio de la terapia antimicrobiana en uso y la reevaluación clínica y de laboratorio del paciente.

En los pacientes con evolución desfavorable el tratamiento será ajustado de acuerdo a:

Hallazgos bacteriológicos: Cualquiera sea el hallazgo bacteriológico, debe continuarse con terapia antimicrobiana asociada y activa sobre bacilos gram negativos y cocáceos gram positivos, según los patrones de susceptibilidad institucional, así se evitará nueva sobreinfección hasta superar la neutropenia.

Aparición de un nuevo foco infeccioso: Se recomienda presuponer las etiologías más probables según sean los hallazgos clínicos (Tabla 5) y ajustar la terapia considerando la experiencia de cada institución y los patrones de susceptibilidad in vitro.

Paciente sin nuevo foco infeccioso: Como en el caso anterior se recomienda ajustar la terapia antimicrobiana de acuerdo a la epidemiología institucional de las infecciones y su patrón de susceptibilidad in vitro.

En cualquiera de las situaciones anteriores se justifica un cambio de terapia antimicrobiana antes de 72 horas de haber sido instaurada si el paciente presenta agravamiento clínico evidente o shock séptico, en cuyo caso se sugiere traslado a UCI y cambio a alternativas terapéuticas de segunda línea, que deben considerar como fármaco anti bacilos gramnegativos ciprofloxacina, cefalosporinas de $4^{\circ}$ generación (cefepime) o carbapenem (imipenem o meropenem) y vancomicina como terapia frente a cocáceas grampositivas.

Sospecha y manejo de infecciones fúngicas profundas. La mayoría de los pacientes pediátricos con episodios de NF se encuentran en vías de recuperación de su neutropenia severa y están afebriles al séptimo día de evolución. La prolongación de la fiebre y la neutropenia severa más allá de 7 días, unido al uso de antimicrobianos de amplio espectro y la mucositis por quimioterapia, favorecen el surgimiento de infecciones fúngicas invasoras (IFI), difíciles de objetivar.

En todo niño que se mantiene febril y con RAN $<500 / \mathrm{mm}^{3}$ al $7^{\circ}$ día de hospitalización, se realizará hemocultivos siguiendo la pauta de ingreso, urocultivo, búsqueda de hifas en orina, cultivos de lesiones que existiesen en piel y mucosas; fondo de ojo; estudio por imágenes de acuerdo a la orientación clínica: ecocardiografía, TAC de abdomen y tórax, TAC de cavidades paranasales. Además es recomendable iniciar terapia antifúngica empírica, mientras se efectúa la documentación de la IFI. La terapia antifúngica ampliamente recomendada es anfotericina $\mathrm{B}$, adicionada a la terapia antibacteriana. Una vez iniciada la terapia antifúngica, ésta se continuará por al menos 14 días en niños en que se confirme el diagnóstico de IFI (por imágenes o microbiología). En pacientes en que todo el estudio propuesto para búsqueda de IFI el día 7 de evolución de NF sea negativo, deberá repetirse el estudio al tercer a quinto día de evolución de la terapia antifúngica (día 10 a 14 de evolución de la NF). Si esta exploración resulta nuevamente negativa, se sugiere suspender la terapia antifúngica. Otras terapias alternativas en pacientes con IFI son fluconazol, caspofungina y voriconazol, dependiendo de la enfermedad de base, las condiciones clínicas del paciente y la fase de tratamiento del cáncer.

\section{Pacientes con bajo riesgo de infección bacteriana invasora (Figura 1)}

Se recomienda su manejo intrahospitalario las primeras 24 a 48 horas, seguido de tratamiento ambulatorio si el paciente conserva hasta ese momento criterios de bajo riesgo. En establecimientos que carezcan de experiencia o infraestructura para implementar un programa de manejo ambulatorio con un buen seguimiento, se recomienda mantener al niño hospitalizado hasta la resolución de su episodio de NF.

Tratamiento antimicrobiano. Para la etapa de manejo intrahospitalario de estos pacientes es apropiada la ceftriaxona iv, por su espectro antibacteriano y su facilidad de administración cada 24 horas. Para la etapa de manejo ambulatorio se recomienda ceftriaxona iv, por las razones ya descritas, o terapia oral en base a cefuroxima axetil, amoxicilina/ácido clavulánico, ciprofloxacina $u$ otra alternativa de acuerdo al foco clínico 
Tabla 6. Dosis recomendadas de antimicrobianos en niños con neutropenia febril

\begin{tabular}{|c|c|c|c|}
\hline Antimicrobiano & $\begin{array}{c}\text { Dosis } \\
\mathrm{mg} / \mathrm{kg} / \mathrm{día}\end{array}$ & $\begin{array}{l}\text { Frecuencia } \\
\text { (horas) }\end{array}$ & Observaciones \\
\hline $\begin{array}{l}\text { Penicilinas } \\
\text { Amoxicilina } \\
\text { Amoxicilina/ác clavulánico } \\
\text { Ampicilina } \\
\text { Cloxacilina } \\
\text { Penicilina } \\
\text { Piperacilina/tazobactam } \\
\text { Ticarcilina/ác clavulánico }\end{array}$ & $\begin{array}{c}50-80 \\
50-80 \\
100-400 \\
100 \\
100.000-250.000 \mathrm{U} \\
200-400 \\
200-400\end{array}$ & $\begin{array}{l}\mathrm{c} / 8-12 \\
\mathrm{c} / 8-12 \\
\mathrm{c} / 6 \\
\mathrm{c} / 6 \\
\mathrm{c} / 4-6 \\
\mathrm{c} / 6 \\
\mathrm{c} / 6\end{array}$ & $\begin{array}{l}\text { Dosis altas } S . \text { pneumoniae } \mathrm{R} \\
\text { Dosis altas } S . \text { pneumoniae } \mathrm{R} \\
\text { Dosis altas en meningitis } \\
\\
\text { Dosis altas en meningitis } \\
\text { Dosis altas en infecciones severas } \\
\text { Dosis altas en infecciones severas }\end{array}$ \\
\hline $\begin{array}{l}\text { Cefalosporinas } \\
\text { Cefadroxilo } \\
\text { Cefuroxima axetil } \\
\text { Cefotaxima } \\
\text { Ceftriaxona } \\
\text { Cefoperazona/sulbactam } \\
\text { Ceftazidima } \\
\text { Cefepime }\end{array}$ & $\begin{array}{rr}30- & 50 \\
30- & 50 \\
100- & 300 \\
50- & 100 \\
50-150 \\
100-150 \\
50-150\end{array}$ & $\begin{array}{l}\mathrm{c} / 12 \\
\mathrm{c} / 12 \\
\mathrm{c} / 6-8 \\
\mathrm{c} / 24 \\
\mathrm{c} / 6-12 \\
\mathrm{c} / 6-8 \\
\mathrm{c} / 8\end{array}$ & $\begin{array}{l}\text { Uso oral } \\
\text { Uso oral } \\
\text { Dosis altas en meningitis } \\
\text { Dosis altas en meningitis } \\
\text { Asociar vitamina K } \\
\text { Dosis altas en infecciones severas }\end{array}$ \\
\hline $\begin{array}{l}\text { Carbapenem } \\
\text { Imipenem } \\
\text { Meropenem }\end{array}$ & $\begin{array}{l}60 \\
60\end{array}$ & $\begin{array}{l}\mathrm{c} / 6 \\
\mathrm{c} / 8\end{array}$ & Favorece convulsiones \\
\hline $\begin{array}{l}\text { Aminoglucósidos } \\
\text { Amikacina } \\
\text { Gentamicina }\end{array}$ & $\begin{array}{r}15 \\
5-7\end{array}$ & $\begin{array}{l}c / 12-24 \\
c / 12-24\end{array}$ & \\
\hline $\begin{array}{l}\text { Quinolonas } \\
\text { Ciprofloxacina }\end{array}$ & $20-40$ & $c / 12$ & $20 \mathrm{mg} / \mathrm{kg}$ iv, $40 \mathrm{mg} / \mathrm{kg}$ oral \\
\hline $\begin{array}{l}\text { Glicopéptidos } \\
\text { Vancomicina } \\
\text { Teicoplanina }\end{array}$ & $\begin{array}{c}40-60 \\
10\end{array}$ & $\begin{array}{l}c / 6 \\
c / 24\end{array}$ & $\begin{array}{l}\text { Dosis altas en meningitis } \\
1^{\circ} \mathrm{s} \text { dos dosis } \mathrm{c} / 12 \mathrm{hrs}\end{array}$ \\
\hline $\begin{array}{l}\text { Macrólidos } \\
\text { Eritromicina } \\
\text { Claritromicina }\end{array}$ & $\begin{array}{l}50 \\
15\end{array}$ & $\begin{array}{l}c / 6 \\
c / 12\end{array}$ & \\
\hline $\begin{array}{l}\text { Lincosamidas } \\
\text { Clindamicina }\end{array}$ & $30-50$ & $\mathrm{c} / 8$ & \\
\hline $\begin{array}{l}\text { Sulfo-derivados } \\
\text { Cotrimoxazol }\end{array}$ & $\begin{array}{r}8 / 40^{*} \\
20 / 100\end{array}$ & $\begin{array}{l}c / 12 \\
c / 6\end{array}$ & $\begin{array}{l}\text { En neumonía por } \\
\text { Pneumocystis jiroveci }\end{array}$ \\
\hline $\begin{array}{l}\text { Otros } \\
\text { Metronidazol } \\
\text { Rifampicina } \\
\text { Linezolid }\end{array}$ & $\begin{array}{c}20-30 \\
10-20 \\
30\end{array}$ & $\begin{array}{l}c / 8 \\
c / 12 \\
c / 8-12\end{array}$ & iv/oral \\
\hline
\end{tabular}

*Trimetoprim/sulfametoxazol

Tabla 7. Dosis recomendadas de fármacos anti virales en niños con neutropenia febril

\begin{tabular}{lccl}
\hline Fármaco & Dosis $(\mathbf{m g} / \mathbf{k g} / \mathbf{d i ́ a})$ & Frecuencia $(\mathbf{h r s})$ & Observaciones \\
\hline Aciclovir iv & $1.500 \mathrm{mg} / \mathrm{m}^{2}$ & $\mathrm{c} / 8$ & Tratamiento varicela \\
Aciclovir oral & $50-80$ & $\mathrm{c} / 8$ & En profilaxis varicela \\
Ganciclovir iv & 10 & $\mathrm{c} / 12$ & Enfermedad por CMV \\
Foscarnet iv & 180 & $\mathrm{c} / 8$ & Enfermedad por CMV \\
Valaciclovir oral & 60 & $\mathrm{c} / 8$ & Alternativa a aciclovir iv \\
\hline
\end{tabular}


Tabla 8. Dosis recomendadas de fármacos antifúngicos en niños con neutropenia febril

\begin{tabular}{lccc}
\hline Antifúngico & $\begin{array}{c}\text { Dosis } \\
\text { mg/kg/día } \\
\text { (dosis máximas) }\end{array}$ & $\begin{array}{c}\text { Frecuencia } \\
\text { (horas) }\end{array}$ & Observaciones \\
\hline $\begin{array}{l}\text { Anfotericinas } \\
\text { Anfotericina B }\end{array}$ & $0,75-1(1,5)$ & $\mathrm{c} / 24$ & Infusión en 6 horas \\
Anfotericina liposomal & $3-5(10)$ & $\mathrm{c} / 24$ & Infusión en 1 hora \\
Equinocandinas & $50 \mathrm{mg} / \mathrm{m}^{2}$ & $\mathrm{c} / 24$ & \\
Caspofungina & & & \\
Azoles & $6-12 / 3-4$ & $\mathrm{c} / 24$ & Dosis carga/mantención \\
Fluconazol iv-oral & $5-10$ & $\mathrm{c} / 12-24$ & Dosis carga/mantención \\
Itraconazol iv-oral & $12 / 8$ & $\mathrm{c} / 12$ & < $\mathrm{kg} />40 \mathrm{~kg}$ \\
Voriconazol iv & $200 / 400$ & $\mathrm{c} / 12$ & No dosificado por peso \\
Voriconazol oral & & & \\
\hline
\end{tabular}

detectado y a la epidemiología local (Dosis y frecuencia de administración de antimicrobianos en Tabla 6).

Seguimiento de los pacientes. Transcurrida la etapa de manejo intrahospitalario ( 24 a 48 horas), si el paciente mantiene parámetros de bajo riesgo y se ha comprobado la negatividad de los cultivos de sangre y orina, podrá continuar manejo ambulatorio. Todos los pacientes serán evaluados hasta que cumplan 48 horas afebriles y el RAN sea $>500 / \mathrm{mm}^{3}$.

El paciente manejado en forma ambulatoria debe concurrir diariamente a reevaluación por su médico tratante. Los días no hábiles se mantendrá en contacto telefónico con el equipo profesional (médico/enfermera) para un reporte diario y eventual consulta en una unidad de emergencia. Si en el estudio de ingreso se objetiva la presencia exclusiva de una infección viral como causa de la fiebre, se recomienda suspender el tratamiento antimicrobiano, dar de alta y efectuar seguimiento diario hasta la resolución de la neutropenia.

Todos los niños con NF de bajo riesgo se someterán a la siguiente evaluación:

Evaluación clínica. Debe contemplar control del estado hemodinámico, temperatura y búsqueda acuciosa de posibles focos de infección.

Medición seriada de PCR. Se debe realizar los días 2 y 3 y, de allí en adelante, de acuerdo a evolución clínica.

Control hematológico. Se debe medir RAN, RAM y recuento de plaquetas al día 2 , y luego cada dos días, hasta que el RAN sea $>500 / \mathrm{mm}^{3}$,
RAM $>100 / \mathrm{mm}^{3}$, y el recuento de plaquetas $>50.000 / \mathrm{mm}^{3}$.

Evaluación de la respuesta terapéutica. La eficacia del tratamiento antimicrobiano deberá ser evaluado luego de 72 horas de instaurado, y luego al día 5 y 7 de evolución. En estas evaluaciones, la evolución debe ser catalogada como favorable o desfavorable (Definición de evolución favorable o desfavorable en párrafo sobre NF con alto riesgo de IBI).

Los pacientes con evolución favorable continuarán su terapia antimicrobiana con ceftriaxona iv o terapia oral, hasta que estén afebriles por 24 a 48 horas horas y el RAN sea > a 500/ $\mathrm{mm}^{3}$.

Los pacientes con evolución desfavorable serán reevaluados, ajustando su terapia antimicrobiana, y serán hospitalizados si se había adoptado en ellos una modalidad de manejo ambulatorio. Se recomienda en este caso uso de antimicrobianos iv, de amplio espectro, en base a un $\beta$ lactámico con acción anti estafilocóccica más una cefalosporina de $3^{\circ}$ generación y/o un aminoglicósido. Alternativas recomendables son: cloxacilina + amikacina + cefotaxima; cloxacilina + amikacina +ceftazidima.

En pacientes con foco clínico evidente se recomienda adicionar a la terapia de amplio espectro antibacteriano el fármaco más indicado según el foco existente (Tabla 5).

\section{Resumen}

El manejo de los pacientes pediátricos con cáncer y neutropenia febril (NF) requiere de su clasificación en alto o bajo riesgo de adquirir infecciones bacte- 
rianas invasoras (IBI), con el fin de implementar estrategias selectivas de tratamiento. Basados en nuestra experiencia y publicaciones internacionales al respecto, proponemos recomendaciones para el diagnóstico y manejo de niños con cáncer y NF, categorizadas según riesgo de IBI. Todos los pacientes pediátricos que presenten episodios de NF deben ser ingresados al hospital por al menos 24 horas. Durante este lapso se efectuará su evaluación clínica y de laboratorio con el objeto de clasificar el riesgo de este episodio y precisar el (los) posible(s) foco(s). Los pacientes de alto riesgo deben continuar internados hasta su recuperación. Los de bajo riesgo pueden ser manejados en forma ambulatoria. La elección de la terapia antimicrobiana inicial y los criterios para su ajuste deberán basarse en el hallazgo o no de focos infecciosos y en los patrones epidemiológicos e institucionales de susceptibilidad. La reevaluación de ambos grupos debe ser periódica (al menos en los días 3, 5 y 7 de evolución), y la respuesta terapéutica será clasificada como favorable o desfavorable según criterios clínicos y parámetros de laboratorio preestablecidos.

\section{Bibliografía}

1.- Pizzo P A, Rubin M, Freifeld A, et al. The child with cancer and infection I. Empiric therapy for fever and neutropenia, and preventive strategies. J Pediatr 1991; 119: 679-94.

2.- Santolaya M E. Neutropenia febril en el niño con cáncer. Conceptos actuales sobre criterios de riesgo y manejo selectivo. Rev Méd Chile 2001; 129: 144954

3.- Kern W. Risk assessment and risk-based therapeutic strategies in febrile neutropenia. Curr Opin Infect Dis 2001; 14: 415-22.

4.- Klaassen R J, Goodman T R, Pham B, et al. "Lowrisk" prediction rule for pediatric oncology patients presenting with fever and neutropenia. J Clin Oncol 2000; 18: 1012-9.
5.- Klastersky J, Paesmans M, Rubenstein E B, et al. The Multinational Association for Supportive Care in Cancer risk index: a multinational scoring system for identifying low-risk febrile neutropenic cancer patients. J Clin Oncol 2000; 18: 3038-51.

6.- Santolaya M E, Villarroel M, Avendaño L, et al. Discontinuation of antimicrobial therapy for febrile, neutropenic children with cancer: A prospective study. Clin Infect Dis 1997; 25: 92-7.

7.- Tordecilla J, Campbell M, Joannon S, et al. Criterios de alta precoz en niños con cáncer y neutropenia febril. Rev Chil Pediatr 1998; 69: 247-51.

8.- Petrilli A S, Dantas L S, Campos M C, et al. Oral ciprofloxacin $v s$ intravenous ceftriaxone administered in an outpatient setting for fever and neutropenia in low-risk pediatric oncology patients: randomized prospective trial. Med Pediatr Oncol 2000; 34: 8791.

9.- Paganini H, Gómez S, Ruvinsky S, et al. Outpatient, sequential, parenteral-oral antibiotic therapy for lower risk febrile neutropenia in children with malignant diseases. Cancer 2003; 97: 1775-80.

10.- Santolaya M E, Álvarez A M, Becker A, et al. Prospective, multicenter evaluation of risk factors associated with invasive bacterial infection in children with cancer, neutropenia and fever: J Clin Oncol 2001; 19: 3415-21.

11.- Santolaya M E, Álvarez A M, Avilés C L, et al. Prospective evaluation of a model of prediction of invasive bacterial infection risk among children with cancer, fever and neutropenia. Clin Infect Dis 2002; 35: $678-83$.

12.- Santolaya M E, Álvarez A M, Avilés C L, et al. Early hospital discharge followed by outpatient management versus continued hospitalization of children with cancer, fever, and neutropenia at low risk for invasive bacterial infection. J Clin Oncol 2004, in press

13.- Payá E, Álvarez A M, Avilés C L, et al. Agentes causantes de infecciones del torrente circulatorio en niños con cáncer, en cinco hospitales de Santiago (1994-1998). Rev Méd Chile 2001; 129: 1297-304.

14.- García P, Payá E, Olivares R, Coteras A, Rodríguez J, Sanz M. Diagnóstico de las infecciones asociadas a catéteres vasculares centrales. Rev Chil Infect 2003; 20: $41-50$.

Correspondencia a:

María Elena Santolaya de Pablo

E-mail:msantola@med.uchile.cl 